\title{
PET Imaging of Proliferation with Pyrimidines
}

\author{
Omid S. Tehrani and Anthony F. Shields \\ Department of Oncology, Karmanos Cancer Institute, Wayne State University, Detroit, Michigan
}

Learning Objectives: On successful completion of this activity, participants should be able to discuss (1) the radiopharmaceuticals used to evaluate cell proliferation; (2) the normal biodistribution of these radiopharmaceuticals; and (3) the role of these radiopharmaceuticals in the evaluation of malignancies.

Financial Disclosure: This work was partially supported by grant CA22453 from the National Cancer Institute and by U.S. Department of Defense Award W81XWH-10-2-0068. The authors of this article have indicated no other relevant relationships that could be perceived as a real or apparent conflict of interest.

CME Credit: SNMMI is accredited by the Accreditation Council for Continuing Medical Education (ACCME) to sponsor continuing education for physicians. SNMMI designates each JNM continuing education article for a maximum of 2.0 AMA PRA Category 1 Credits. Physicians should claim only credit commensurate with the extent of their participation in the activity. For CE credit, participants can access this activity through the SNMMI Web site (http:// www.snmmi.org/ce_online) through June 2016.

Several new tracers are being developed for use with PET to assess pathways that are altered in cancers, including energy use, cellular signaling, transport, and proliferation. Because increased proliferation is a hallmark of many cancers, several tracers have been tested to track the DNA synthesis pathway. Thymidine, which is incorporated into DNA but not RNA, has been used in laboratory studies to measure tumor growth. Because thymidine labeled with ${ }^{11} \mathrm{C}$ undergoes rapid biologic degradation and has a short physical half-life, tracers labeled with ${ }^{18} \mathrm{~F}$ have been preferred in PET imaging. One such tracer is ${ }^{18} \mathrm{~F}$-labeled $3^{\prime}$-deoxy-3'-fluorothymidine $\left({ }^{18} \mathrm{~F}-\mathrm{FLT}\right) .{ }^{18} \mathrm{~F}-\mathrm{FLT}$ is trapped after phosphorylation by thymidine kinase 1, whose expression is increased in replicating cells. Several studies on breast, lung, and brain tumors have demonstrated that retention of ${ }^{18} \mathrm{~F}-\mathrm{FLT}$ correlated with tumor proliferation. Although ${ }^{18} \mathrm{~F}-\mathrm{FLT}$ has been used to image and stage several tumor types, the standardized uptake value is generally lower than that obtained with ${ }^{18} \mathrm{~F}-\mathrm{FDG}$. ${ }^{18} \mathrm{~F}-\mathrm{FLT}$ can be used to image many areas of the body, but background uptake is high in the liver, marrow, and renal system, limiting use in these organs. ${ }^{18} \mathrm{~F}$-FLT PET imaging has primarily been studied in the assessment of treatment response. Rapid declines in ${ }^{18} \mathrm{~F}-\mathrm{FLT}$ retention within days to weeks have been demonstrated in several tumor types treated with cytotoxic drugs, targeted agents, and radiotherapy. Further work is ongoing to validate this approach and determine its utility in the development of new drugs and in the clinical evaluation of standard treatment approaches.

Key Words: PET; proliferation; thymidine; FLT

J Nucl Med 2013; 54:903-912

DOI: 10.2967/jnumed.112.112201

I cations. In normal tissues with high growth rates, imaging may help with assessment of the proliferation and health of that

Received Mar. 13, 2013; revision accepted May 2, 2013.

For correspondence or reprints contact: Anthony F. Shields, Karmanos

Cancer Institute, 4100 John R St., HW04HO Detroit, MI 48201.

E-mail: shieldsa@karmanos.org

Published online May 14, 2013.

COPYRIGHT @ 2013 by the Society of Nuclear Medicine and Molecular Imaging, Inc. tissue. Because tumors are an accumulation of cells due to increased proliferation or decreased cell death, high proliferation found in unexpected locations may indicate neoplastic growth. Several labeled molecular tracers have been developed for routine and research uses in medicine, but at present only ${ }^{18} \mathrm{~F}$-FDG has come into routine use with PET in oncology. ${ }^{18}$ F-FDG tracks general cellular metabolism, which may correlate with proliferation in some tumors. However, ${ }^{18} \mathrm{~F}-\mathrm{FDG}$ does not provide a direct measure of cell growth. This review will discuss PET tracers used in proliferation imaging, although the main focus will be on ${ }^{18}$ F-labeled $3^{\prime}$-deoxy-3'-fluorothymidine ( $\left.{ }^{18} \mathrm{~F}-\mathrm{FLT}\right)$ PET, which is being increasingly evaluated in several areas of medicine as a proliferation tracer (Fig. 1).

\section{PROLIFERATION IMAGING AND ITS ROLE IN PRACTICE}

Measurement of proliferation, either in normally proliferating tissues or in abnormally growing neoplastic lesions, is an important part of evaluating tissue function and characteristics. For imaging purposes, one way to measure proliferation is to determine the change in the anatomic size of a tumor, as is routinely done with CT and MR imaging, as well as ultrasonography. Limitations in assessing tumor size include the delayed growth seen with viable tumors and the possibility that cell death may not result in early shrinkage of tumors. This is an increasingly common problem with antivascular and other targeted agents, which may cause changes in tumor density or turn off growth-signaling pathways. Tumor size may be unchanged or actually increase. Thus, other methods have been developed to determine metabolic activity by measuring blood flow (using dynamic contrast MR or CT) and energetics (using MR spectroscopy and PET). Another marker of cell growth and proliferation is uptake of the molecules that are needed for synthetic pathways, including labeled amino acids for measuring transport and protein synthesis and nucleosides for DNA synthesis.

Tracing the uptake of these molecules in vivo has been the basis of nuclear proliferation imaging. Among the various methods of nuclear imaging, PET is the most sensitive and accurate and has become more widely available. 


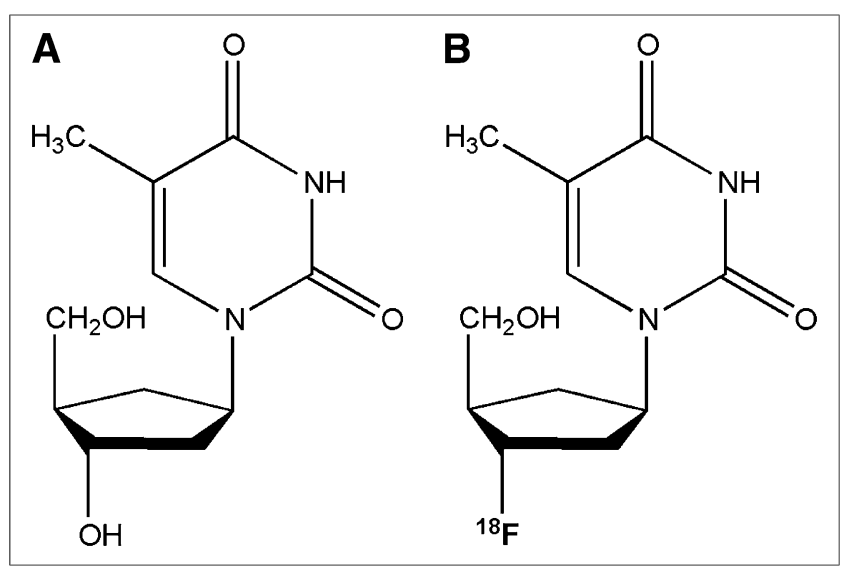

FIGURE 1. Structures of thymidine (A) and ${ }^{18} \mathrm{~F}-\mathrm{FLT}(\mathrm{B})$ with fluoride in position of hydroxide. Fluorine substitution allows labeling with ${ }^{18} \mathrm{~F}$.

In evaluating the relatively low-resolution images, one should note that tumors are heterogeneous tissues and that some parts proliferate whereas others may die. The low resolution of nuclear techniques may result in an image showing a combination of viable and nonviable tissue, which can vary even at the microscopic level. The final image is a mixture, which usually favors the dominant component. Although PET is generally combined with other highresolution modalities such as $\mathrm{CT}$, this combination provides improved anatomic localization but does not alter the characterization of the metabolic activity $(1,2)$.

Metabolic imaging of tumors is based on higher energy consumption and higher uptake of the molecules that dividing cells use in synthesis. Among the most commonly used methods in metabolic imaging are tracers to assess glucose transport $\left({ }^{18} \mathrm{~F}-\mathrm{FDG}\right)$, choline kinase activity $\left({ }^{11} \mathrm{C}\right.$ choline), amino acid transport $\left({ }^{11} \mathrm{C}\right.$-methionine), and activity of thymidine kinase 1 ( ${ }^{18} \mathrm{~F}$-FLT). Cells use nucleosides to synthesize DNA. Among the nucleosides, thymidine is exclusively used in the DNA structure. After entering the cells by multiple different transporters passively or actively $(3,4)$, thymidine is phosphorylated into a more polarized molecule and cannot freely exit the cells. This mechanism has been used to accurately measure DNA synthesis in cell cultures using ${ }^{3} \mathrm{H}$-thymidine. Its use in nuclear imaging, when labeled with ${ }^{11} \mathrm{C}$, has been limited by the short half-life of the tracer and its rapid catabolism in the body (5). This limitation has led to development of newer thymidine analogs. The most accepted thymidine analog for proliferation imaging is ${ }^{18} \mathrm{~F}$-FLT. Like thymidine uptake, ${ }^{18} \mathrm{~F}$-FLT uptake correlates with the $\mathrm{S}$ phase. ${ }^{18} \mathrm{~F}$-FLT incorporation into the DNA fraction is negligible (0.2\%) (6). A meta-analysis of the studies on ${ }^{18} \mathrm{~F}$-FLT uptake and tumors expressing Ki-67 showed a persistent correlation between them (7). These examples demonstrate the uniqueness of tracers and how they may be applied to medicine. Another thymidine analog, 1-( $2^{\prime}$-deoxy- $2^{\prime}$-fluoro- $\beta$-D-arabinofuranosyl) thymine, is phosphorylated by mitochondrial thymidine kinase 2 , incorporates into DNA, and may measure cell stress and viability. In contrast to animal studies, in human subjects uptake of this analog is high in the tumor and low in the bone marrow. Although partially due to faster clearance from the bloodstream and different kinetics, the main reason may be the higher activity of mitochondrial thymidine kinase 2 in human cells $(8)$.

Imaging of tumor proliferation can be applied in decision making on prognosis and treatment options. Finding a specific tracer for proliferation has been a challenge. Tracer uptake relies on an understanding of both pharmacokinetics and pharmacodynamics. One major challenge has been to correlate what is happening in cell cultures and preclinical studies with clinical studies $(9,10)$. Because of the higher sensitivity of PET, positron-emitting tracers have attracted interest for widespread use. An interesting application of proliferation imaging studies has been to predict the response to treatment based on imaging values obtained during the course of treatment. The basis of this thought is that treatment-induced changes in tumor physiology will predict tumor cell viability earlier than anatomic imaging.

\section{BONE MARROW AND HEMATOLOGIC MALIGNANCIES}

${ }^{18}$ F-FLT has high uptake in proliferating tissue, including bone marrow (11). Although this review discusses some studies about detecting bone tumors and metastases, bone marrow uptake is one of the limiting factors in applying ${ }^{18}$ F-FLT PET in cancer staging, along with liver uptake. However, ${ }^{18}$ F-FLT PET also has been used to measure the health and proliferation of the marrow, especially in patients undergoing bone marrow transplantation (12). ${ }^{18} \mathrm{~F}$-FLT PET imaging was found useful in evaluating bone marrow in patients with aplastic anemia (13). Interestingly, the main characteristic of ${ }^{18} \mathrm{~F}$-FLT PET in patients with extramedullary hematopoiesis was higher uptake in the spleen and liver (14). One major side effect of many cancer treatments is bone marrow suppression. ${ }^{18} \mathrm{~F}$-FLT uptake has been shown to decrease after radiation, especially in areas with active marrow, including the skull and pelvis (15-17). In patients undergoing radiation treatment, both the profile and the individual vertebral data have shown a strong correlation between change in ${ }^{18} \mathrm{~F}$-FLT uptake and radiation dose. The reduction in standardized uptake value (SUV) was approximately linear with radiation dose (17).

In one study (18), ${ }^{18}$ F-FLT PET was used to assess patients with leukemia, in whom uptake was higher in leukemic marrow (SUV, 6.6) than in normal marrow (SUV, 1.5). In this study of 10 patients, extramedullary disease was also accurately noted in 4 patients. Leptomeningeal disease has been seen in a patient with lymphoma using ${ }^{18}$ F-FLT PET (19). ${ }^{18}$ F-FLT PET is now being explored to determine whether patients with acute leukemia have achieved marrow ablation, which is predictive of remission (20). Patients with acute myelogenous leukemia who do not achieve remission after the first induction course are generally given a second course of intensive chemotherapy. The most common approach for early evaluation of treatment has been to obtain a bone marrow biopsy on day 14 of treatment. 
Unfortunately, histologic marrow assessment at day 14 does a relatively poor job at predicting remission at $28 \mathrm{~d}$. In one study, of patients with evidence of residual leukemia in day 14 marrow, $36 \%$ achieved complete remission, whereas $21 \%$ without leukemia on the early marrow did not reach remission (21). A pilot study on 7 patients imaged with ${ }^{18}$ F-FLT PET immediately after completion of induction chemotherapy was able to accurately predict remission (5 patients) or relapse (2 patients) at 1 mo (Fig. 2) (20). A more accurate determination of remission status early after treatment would help direct treatment, and this approach is being further explored.

In a study of 66 patients with non-Hodgkin lymphoma, the relative uptake of ${ }^{18} \mathrm{~F}$-FLT before the start of therapy was predictive of the ultimate response to treatment, with those achieving complete response having a lower mean SUV of 7.1, compared with 9.5 in the other patients $(P=$ 0.049) (Fig. 3) (22). In another study of non-Hodgkin lymphoma, staging with ${ }^{18}$ F-FLT PET/CT had a higher sensitivity and specificity than CT alone (23). In this study of 38 patients, ${ }^{18}$ F-FLT PET and CT agreed in $79 \%$ of the lesions, but PET had better sensitivity and specificity although no comparison was made with ${ }^{18} \mathrm{~F}$-FDG PET.

${ }^{18}$ F-FLT has also shown a good correlation with proliferation and response to therapy in lymphoma. In mice implanted with human diffuse B-cell lymphoma, ${ }^{18} \mathrm{~F}$-FLT uptake decreased by day 2 after treatment with doxorubicin, compared with control mice and baseline scans. Furthermore, the decrease in ${ }^{18} \mathrm{~F}$-FLT retention correlated with an increased dose of doxorubicin, whereas there were variable changes in ${ }^{18}$ F-FDG retention. In patients with high-grade non-Hodgkin lymphoma, treatment with $\mathrm{CHOP} / \mathrm{R}-\mathrm{CHOP}$ (rituximab, cyclophosphamide, hydroxydaunomycin, vincristine, and prednisone) resulted in a $77 \%$ decrease in retention by day 7 (24). In patients who initially received rituximab (before starting $\mathrm{CHOP}$ ), there was no decrease in ${ }^{18} \mathrm{~F}$-FLT by day 2 . Increased ${ }^{18} \mathrm{~F}$-FLT uptake was also noted in patients with mantel cell lymphoma, along with rapid declines in retention after 1 wk of therapy (22).

\section{SARCOMAS}

Even though ${ }^{18}$ F-FLT uptake in normal bone marrow might interfere with imaging of tumors involving the bone, such does not appear to be an issue in sarcomas. In 2 studies of patients with bone or soft-tissue sarcomas, all tumors were visualized in 36 patients $(25,26)$. Both studies showed that ${ }^{18} \mathrm{~F}$-FLT uptake correlated with grade whereas ${ }^{18} \mathrm{~F}$ FDG uptake did not. An ${ }^{18}$ F-FLT SUV cutoff of 2.0 was able to differentiate high- from low-grade tumors $(25) .{ }^{18} \mathrm{~F}$ FLT PET has also been used to assess response in patients with sarcomas. A study of 10 patients imaged before and after $(\sim 1 \mathrm{mo})$ hyperthermic isolated limb perfusion with chemotherapy demonstrated the treatment effect in all but one patient, with areas of necrosis and decreased ${ }^{18} \mathrm{~F}$-FLT retention (27). In general, patients with higher baseline ${ }^{18} \mathrm{~F}$ FLT uptake responded better to the treatment. On the other

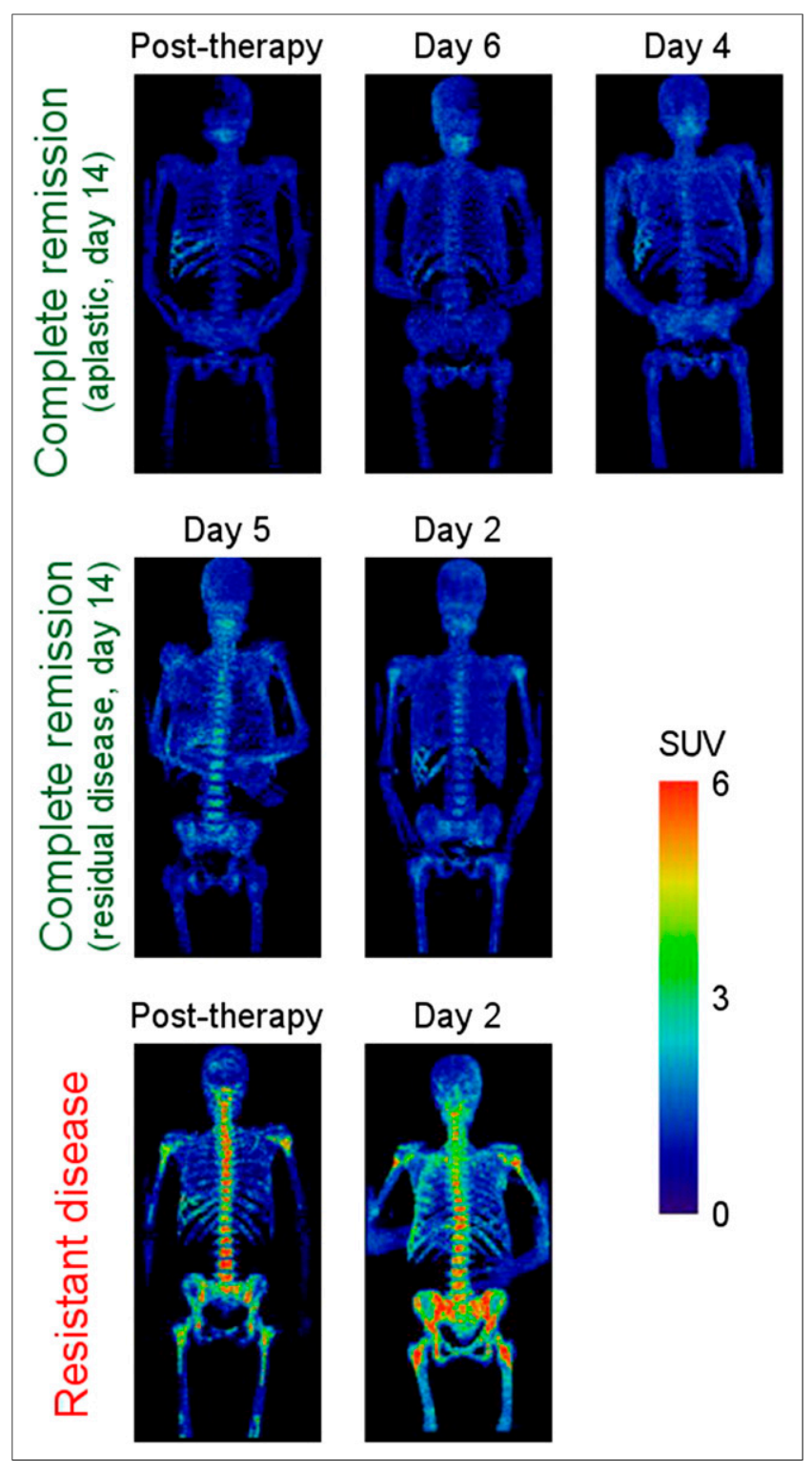

FIGURE 2. ${ }^{18} \mathrm{~F}-\mathrm{FLT}$ PET images of bone marrow of $7 \mathrm{AML}$ patients grouped by clinical response. PET scans were acquired at different time points of therapy, but results were consistent within each clinical response group (complete remission and resistant disease), independent of time of assessment. Resistant disease exhibited elevated uptake, whereas complete remission displayed low uptake. (Reprinted with permission of (20).)

hand, a recent study of 20 patients before and after neoadjuvant chemotherapy for sarcomas did not find that the histologic response was accurately reflected by the change in ${ }^{18}$ F-FLT retention (28). ${ }^{18}$ F-FLT SUV peak declined on average from 7.1 to 2.7 , but the post-treatment retention did not correlate with $\mathrm{Ki}-67$ or thymidine kinase 1 levels. Further work is needed to determine the utility of this approach in sarcomas.

\section{BREAST CANCER}

Although ${ }^{18} \mathrm{~F}$-FDG PET has been regularly used to detect, stage, and evaluate treatment response in patients with 


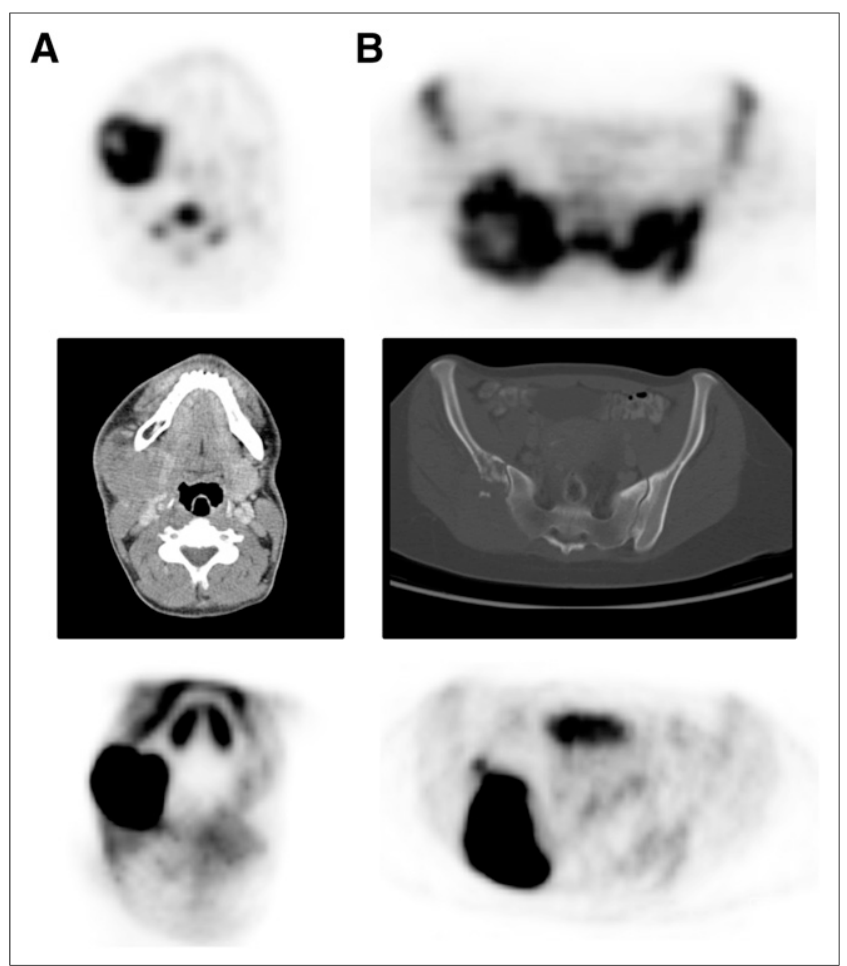

FIGURE 3. Transaxial views of ${ }^{18}$ F-FLT PET (top), helical CT (middle), and ${ }^{18}$ F-FDG PET (bottom) for 2 patients with DLBCL. (A) A 41-yold man with retromandibular lymphoma showing intense ${ }^{18} \mathrm{~F}-\mathrm{FDG}$ and ${ }^{18} \mathrm{~F}$-FLT uptake in projection of retromandibular lymph node. This stage $1 \mathrm{~A}$ patient revealed disease progression under therapy. (B) $A$ 40-y-old woman (stage IVA) with histologically proven lymphoma in right iliac bone and sacrum. ${ }^{18} \mathrm{~F}-\mathrm{FDG}$ PET shows intensely increased uptake in right ilium and sacrum. Corresponding ${ }^{18} \mathrm{~F}-\mathrm{FLT}$ PET images allow detection of increased asymmetric uptake in right ilium and sacrum despite high physiologic ${ }^{18} \mathrm{~F}-\mathrm{FLT}$ uptake in proliferating bone marrow. Transaxial views of helical CT display osteodestruction of right ilium. Restaging after end of therapy revealed complete response. (Reprinted from (22).)

breast cancer, ${ }^{18}$ F-FLT has also been used in several studies. For example, in a study of newly diagnosed patients, 13 of 14 primary lesions and 7 of 8 patients with positive axillary nodes were detectable by ${ }^{18}$ F-FLT (29). Although the average uptake was lower with ${ }^{18}$ F-FLT (SUV, 3.2) than with ${ }^{18} \mathrm{~F}-\mathrm{FDG}$ (SUV, 4.7), the lower background activity in normal breast tissue led to comparable conspicuity. ${ }^{18} \mathrm{~F}$-FLT uptake has been shown to correlate with histologic assessment of proliferation by Ki-67 in breast, lung, and brain cancers in a recent analysis of 27 such studies (7). Changes in ${ }^{18} \mathrm{~F}$-FLT uptake have been detected as early as $1 \mathrm{wk}$ after chemotherapy with 5-fluorouracil, epirubicin, and cyclophosphamide (30). Responding lesions had an average decrease in SUV of $41.3 \%$, whereas in nonresponders the SUV increased by $3.1 \%$. Several methods are available for analyzing images with ${ }^{18} \mathrm{~F}$-FLT to detect changes after chemotherapy, including SUV, tumor-to-whole blood ratio, and nonlinear regression kinetic models (31). In this study of 15 patients with locally advanced breast cancer, tumor-to-whole blood ratio provided a measure that correlated better with dynamic imaging than SUV but still was relatively simple. In the end, the measure to be used will depend on which is the easiest and is able to predict the ultimate clinical response.

\section{CENTRAL NERVOUS SYSTEM CANCERS}

Although MR imaging remains the standard for the evaluation of tumors of the brain, the aggressiveness of tumors is often difficult to determine, particularly in areas that are not viable. Because of the high uptake of ${ }^{18} \mathrm{~F}-\mathrm{FDG}$ in normal brain tissue, there is an interest in using other radiotracers to evaluate tumors of the central nervous system. ${ }^{18} \mathrm{~F}$-FLT has a low background uptake in the normal brain, since it does not readily cross the blood-brain barrier. Although ${ }^{18} \mathrm{~F}$-FLT has found use in the assessment of brain tumors, one must keep in mind that breakdown of this barrier can lead to increased activity in the absence of cell proliferation. A recent study compared ${ }^{18} \mathrm{~F}-\mathrm{FDG},{ }^{18} \mathrm{~F}-\mathrm{FLT}$, and ${ }^{11} \mathrm{C}$-methionine PET tracers in patients with grade IIIV gliomas (32). Although ${ }^{18} \mathrm{~F}-\mathrm{FDG}$ could not be used to differentiate between the different tumor grades, both ${ }^{18} \mathrm{~F}-$ FLT and ${ }^{11} \mathrm{C}$-methionine demonstrated a clear difference. For example, grade II and IV tumors demonstrated increased mean ${ }^{18}$ F-FLT retention with SUVs of 0.36 and 2.38 , respectively, and ${ }^{11} \mathrm{C}-$ methionine retention with SUVs of 3.04 and 5.12, respectively. The areas with high ${ }^{18} \mathrm{~F}$-FLT retention demonstrated an increased $\mathrm{Ki}-67$ index, as was the case for ${ }^{11} \mathrm{C}$-methionine uptake.

Uptake of ${ }^{18} \mathrm{~F}-\mathrm{FLT}$ has been used to evaluate radiation necrosis compared with tumor recurrence, and both ${ }^{18} \mathrm{~F}$ FDG and ${ }^{18} \mathrm{~F}-\mathrm{FLT}$ provided accurate assessments (33).

A study evaluated ${ }^{18}$ F-FLT uptake 2 and 6 wk after treatment with bevacizumab combination therapy in 30 patients with gliomas (Fig. 4) (34) and found that ${ }^{18}$ F-FLT, particularly at $6 \mathrm{wk}$, was the best predictor of overall survival in a multivariant analysis and was more accurate than MR imaging alone. ${ }^{18} \mathrm{~F}-\mathrm{FLT}$ PET responders survived a mean

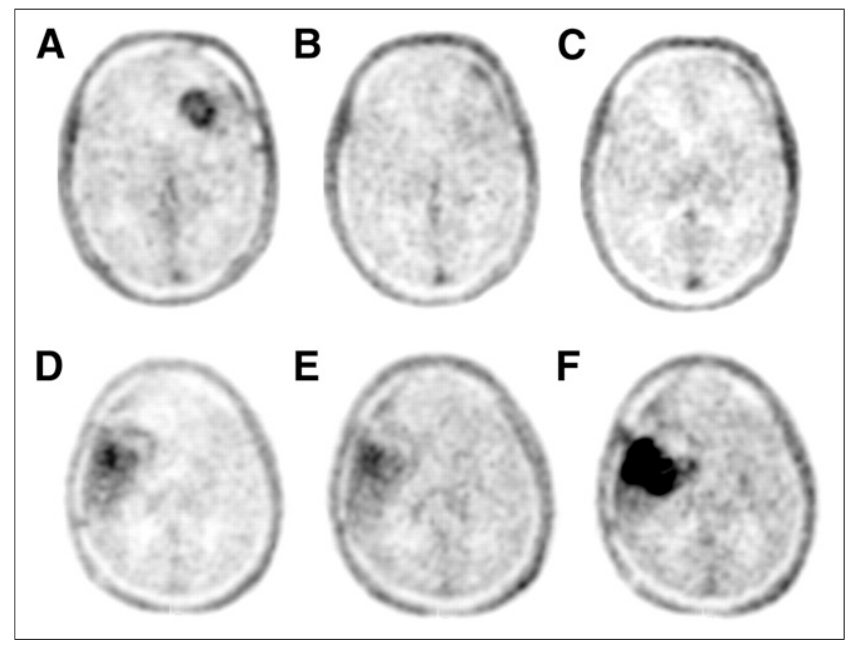

FIGURE 4. ${ }^{18} \mathrm{~F}-\mathrm{FLT}$ PET at baseline, $2 \mathrm{wk}$, and $6 \mathrm{wk}$ for responding patient $(A-C$, patient 25$)$ and nonresponding patient $(D-F$, patient 9). (Reprinted from (34)). 
of $12.5 \mathrm{mo}$, whereas nonresponders survived only $3.8 \mathrm{mo}$ $(P<0.001)$. Another study on ${ }^{18}$ F-FLT PET uptake in recurrent malignant gliomas after bevacizumab treatment also showed that decreased ${ }^{18}$ F-FLT uptake was associated with longer progression-free survival, although the evaluation of overall survival correlated better with ${ }^{18} \mathrm{~F}$-fluoro-L-phenylalanine (35). However, because of relatively low uptake of ${ }^{18}$ F-FLT in brain tumors, disruption of the blood-brain barrier may interfere with proper evaluation of the tumors, since ${ }^{18} \mathrm{~F}$-FLT can be retained in some areas after successful therapy or in benign lesions as well (36). In addition to tumor SUVs, the use of combined ${ }^{18}$ F-FLT kinetic changes has also been suggested for more accurately predicting treatment response, recurrence, and treatment outcome, since these take into account tracer delivery $(37,38)$. This factor may partially explain the high sensitivity and low specificity of ${ }^{18}$ F-FLT in detecting recurrent brain tumors (39).

\section{GASTROINTESTINAL CANCERS}

The use of ${ }^{18} \mathrm{~F}$-FLT in gastrointestinal cancers is limited in part by physiologic retention in the liver, where ${ }^{18} \mathrm{~F}$-FLT is glucuronidated; in the kidneys and bladder, where it is excreted; and in the marrow, where proliferation occurs. Even with these limitations, ${ }^{18}$ F-FLT has shown utility in several studies. In colon cancer, as seen with several other tumor types, ${ }^{18} \mathrm{~F}$-FLT uptake is lower than ${ }^{18} \mathrm{~F}$-FDG uptake, with a mean SUV (SUVmean) of $5.4 \pm 2.4$ and $12.4 \pm 6.3$, respectively $(P<0.003)$, although all cancers were detected (40). This study and one by Francis et al. (41) gave differing results when ${ }^{18} \mathrm{~F}$-FLT uptake and Ki-67 were compared, with the former not demonstrating a correlation whereas the latter did $(r=0.8, P<0.01)$. Although ${ }^{18} \mathrm{~F}$ FLT has been able to detect primary colon cancers, it is clearly limited in the liver because of physiologic retention in that organ (42). In a recent study, ${ }^{18} \mathrm{~F}-\mathrm{FLT}$ and ${ }^{18} \mathrm{~F}-\mathrm{FDG}$ PET were used to evaluate patients receiving neoadjuvant chemoradiotherapy for rectal cancer (43). Although the change in ${ }^{18} \mathrm{~F}$-FLT retention did not predict pathologic response, disease-free survival was predicted by ${ }^{18} \mathrm{~F}$-FLT uptake during therapy and by the percentage decrease but was also predicted by the pretreatment ${ }^{18} \mathrm{~F}-\mathrm{FDG}$ uptake level.

In 22 patients with esophageal squamous cell carcinoma, ${ }^{18} \mathrm{~F}$-FLT and ${ }^{18} \mathrm{~F}$-FDG PET were performed before surgery. ${ }^{18} \mathrm{~F}$-FDG uptake in locoregional lymph node metastases was significantly higher than ${ }^{18} \mathrm{~F}$-FLT uptake $\left({ }^{18} \mathrm{~F}-\mathrm{FDG}\right.$ median maximum SUV [SUVmax], 5.4; range, 2.4-10.6; ${ }^{18}$ F-FLT median SUVmax, 2.8; range, 1.3-4.6). There were 14 false-positives with ${ }^{18} \mathrm{~F}-\mathrm{FDG}$, compared with 3 with ${ }^{18} \mathrm{~F}$ FLT, and 8 false-negatives with ${ }^{18} \mathrm{~F}-\mathrm{FDG}$, compared with 12 with ${ }^{18} \mathrm{~F}$-FLT (44). ${ }^{18} \mathrm{~F}$-FLT also better delineated gross tumor volume for radiation treatment planning, with improved sparing of the lungs and heart (45). In another study, on 10 patients with biopsy-proven esophageal and gastroesophageal cancer, ${ }^{18}$ F-FDG PET was able to detect all esophageal cancers whereas ${ }^{18}$ F-FLT PET visualized the tumor in only 8 of the 10 patients. The ${ }^{18}$ F-FDG SUVmean of about 6.0 was higher than the ${ }^{18}$ F-FLT SUVmean of 3.4, and like the aforementioned study, neither correlated with Ki-67 expression in the linear regression analysis (46). Nevertheless, ${ }^{18}$ F-FLT has been successfully used to image proliferation in esophageal squamous tumors after treatment with radiation and chemotherapy (47). This study showed that ${ }^{18}$ F-FLT uptake rapidly decreased after the start of radiotherapy, as early as after 2 Gy of radiation. Two biopsyproven inflammatory lesions after the end of radiotherapy were still positive on ${ }^{18} \mathrm{~F}$-FDG PET but not on ${ }^{18} \mathrm{~F}$-FLT PET.

Similar to colon and esophageal cancers, gastric cancer has shown lower uptake of ${ }^{18} \mathrm{~F}$-FLT than of ${ }^{18} \mathrm{~F}$-FDG (48). In a series of 45 gastric cancer patients, ${ }^{18} \mathrm{~F}$-FLT and ${ }^{18} \mathrm{~F}-$ FDG PET were performed. The mean SUV for ${ }^{18} \mathrm{~F}-\mathrm{FLT}$ in the primary cancers was 6.0 (range, 2.4-12.7). In ${ }^{18}$ F-FDGpositive tumors, the mean value for ${ }^{18} \mathrm{~F}-\mathrm{FDG}$ was $8.4 \pm 4.1$, versus $6.8 \pm 2.6$ for ${ }^{18} \mathrm{~F}$-FLT (Wilcoxon test, $P=0.03$ ). Interestingly, signet ring cell tumors had similar uptake of both tracers $\left(6.2 \pm 2.1\right.$ for ${ }^{18} \mathrm{~F}$-FLT, vs. $6.4 \pm 2.8$ for ${ }^{18} \mathrm{~F}$ FDG). Although all tumors were visible with ${ }^{18} \mathrm{~F}$-FLT PET, 14 tumors were not detectable with ${ }^{18} \mathrm{~F}-\mathrm{FDG}$ because of high normal gastric uptake. In another study, 21 patients with advanced gastric cancer were imaged with ${ }^{18} \mathrm{~F}$-FLT PET and ${ }^{18}$ F-FDG PET (49). There was no significant correlation between Ki-67 index and the SUV obtained with either tracer. The sensitivities of ${ }^{18} \mathrm{~F}-\mathrm{FLT}$ PET and ${ }^{18} \mathrm{~F}-\mathrm{FDG}$ PET were $95.2 \%$ and $95.0 \%$, respectively. The mean SUV for ${ }^{18} \mathrm{~F}-\mathrm{FDG}, 9.4 \pm 6.3$, was higher than that for ${ }^{18} \mathrm{~F}-\mathrm{FLT}$, $7.0 \pm 3.3(P<0.05)$. In a study of 45 patients, all tumors were visible with ${ }^{18} \mathrm{~F}$-FLT PET, including 14 patients with tumors that were not ${ }^{18} \mathrm{~F}-\mathrm{FDG}$-avid (50). Comparing ${ }^{18} \mathrm{~F}$-FDG with ${ }^{18}$ F-FLT, uptake 2 wk after the initiation of neoadjuvant chemotherapy showed only ${ }^{18}$ F-FLT to have significant prognostic impact and a good correlation with histologic proliferation (Ki-67). The corresponding hazard ratio for the SUVmean of ${ }^{18} \mathrm{~F}-\mathrm{FLT}$ at day 14 was 1.53 (95\% confidence interval, $1.01-2.32 ; P=0.048)$, indicating a risk increment of approximately $50 \%$ with each unit increment of ${ }^{18}$ F-FLT SUVmean. However, neither ${ }^{18}$ F-FLT nor ${ }^{18}$ F-FDG uptake predicted clinical or pathologic response in these gastric tumors treated with neoadjuvant chemotherapy. Such results have generated questions about the mechanisms involved in ${ }^{18}$ F-FLT uptake in gastrointestinal cancers. A study done on 21 patients with newly diagnosed gastrointestinal cancer with ${ }^{18} \mathrm{~F}$-FLT PET demonstrated a significant correlation between ${ }^{18} \mathrm{~F}$-FLT SUV and thymidine kinase 1 (TK1) messenger RNA expression $(P<0.05)(51)$. However, no significant correlation was found between ${ }^{18}$ F-FLT SUV and messenger RNA expression of equilibrating nucleoside transporter $1(P=0.90)$. Well-differentiated endocrine tumors have not been studied extensively, but available data suggest that ${ }^{18} \mathrm{~F}$-FLT is not very helpful in these tumors (52).

Because of the high background uptake in the liver and gallbladder, the application of ${ }^{18}$ F-FLT in imaging hepatobiliary tumors is limited. Studies on primary hepatocellular tumors have shown a mixed uptake pattern for ${ }^{18} \mathrm{~F}-\mathrm{FLT}$. 
About two thirds of the lesions showed ${ }^{18} \mathrm{~F}-\mathrm{FLT}$ uptake higher than in the surrounding liver tissue, with the rest of the lesions being photopenic or a mixture of hot and cold spots. ${ }^{18}$ F-FLT PET imaging in untreated patients with hepatocellular carcinoma (16 patients) and cholangiocarcinoma (2 patients) revealed an SUVmean of 7.8 (range, 2.511.1) and an ${ }^{18}$ F-FLT SUVmax of 9.3 (range, 2.9-14.3) (53). In the subgroup of hepatocellular carcinoma, the sensitivity for tumor detection was $69 \%$ (11/16; $95 \%$ confidence interval, $41 \%-89 \%)$. The Ki-67 score and the ${ }^{18} \mathrm{~F}-\mathrm{FLT}$ SUVmean correlated in these tumors $(r=0.66, P=0.02)$. Like a variety of other cancers, pancreatic cancer has much lower uptake of ${ }^{18} \mathrm{~F}$-FLT than of ${ }^{18} \mathrm{~F}$-FDG, leading to lower sensitivity and higher specificity in differentiating malignant from benign tumors. In a study with 41 patients imaged with ${ }^{18} \mathrm{~F}-\mathrm{FLT}$ and ${ }^{18} \mathrm{~F}$-FDG PET, 33 had pancreatic malignancy, whereas 8 had benign disease (54). Sensitivity values of ${ }^{18} \mathrm{~F}-$ FDG and ${ }^{18}$ F-FLT PET were 91\% (30/33) and 70\% (23/33), respectively. Specificities of these techniques were 50\% (4/8) for ${ }^{18} \mathrm{~F}-\mathrm{FDG}$ and $75 \%(6 / 8)$ for ${ }^{18} \mathrm{~F}$-FLT PET. The average SUVmax in all malignant tumors was 3.0 (range, 1.1-6.5) for ${ }^{18}$ F-FLT and 7.9 (range, 3.3-17.8) for ${ }^{18} \mathrm{~F}-\mathrm{FDG}(P<0.001$. However, these values are technique-dependent. In another study on 31 patients, all 10 benign pancreatic lesions were negative on ${ }^{18}$ F-FLT PET (specificity, $100 \%$; $90 \%$ confidence interval, 74\%-100\%) (55). On visual interpretation, 15 of 21 malignant tumors had higher uptake (sensitivity, $71.4 \%$; $90 \%$ confidence interval, $52 \%-89 \%$ ). To differentiate cancer from benign pancreatic lesions, receiver-operating-characteristic analysis using a SUVmean cutoff of 1.8 had a sensitivity of $81 \%$ and specificity of $100 \%$. Visual discrimination between benign and malignant tumors has proven difficult in other studies with smaller numbers of patients (56). Despite available preclinical studies, further clinical studies are needed to determine diagnostic, prognostic, and histologic relationships with ${ }^{18} \mathrm{~F}$-FLT uptake in pancreatic tumors.

\section{GENITOURINARY CANCERS}

The main issue with imaging the urinary system with ${ }^{18} \mathrm{~F}-\mathrm{FLT}$ PET is the high background uptake, due to excretion in the urine. Unlike preclinical studies, there are limited clinical data in these cancers, although some case studies have shown promising results such as identifying malignancy in renal cysts (57). ${ }^{18} \mathrm{~F}$-FLT uptake after withdrawal of tyrosine kinase inhibitors has been tested in these renal cancers (58). Sixteen patients were imaged during and then after discontinuing sunitinib; median ${ }^{18}$ F-FLT PET SUV increased an average of $15 \%$ (range, $-14 \%-277 \%$; $P=0.047$ ) with the 4-on, 2-off schedule and $+19 \%$ (range, $-5.3 \%-200 \% ; P=0.047$ ) with the 2-on, 1-off schedule. The authors suggested that this increase is consistent with a VEGF receptor tyrosine kinase inhibitor withdrawal flare.

In addition to the mentioned problems in imaging the urinary tract, visualizing ovarian and endometrial tumors in premenopausal women faces another challenge due to periodic physiologic changes of the tissues. Six patients were imaged with ${ }^{18} \mathrm{~F}$-FLT PET in an attempt to differentiate benign from malignant ovarian tissues. SUVmax was higher in malignant tissue (mean, 4.8; range, 1.7-8.8) than in benign tissue (1.65; range, 1.4-1.9) and normal ovarian control tissue (1.12; range, 0.6-1.5) (59). Although there was a trend toward increased ${ }^{18} \mathrm{~F}$-FLT uptake and Ki-67 index in malignant tissues, there has been considerable overlap and further studies will be needed to assess the feasibility of this technique in differentiating benign from malignant ovarian tissues. Clinical studies in germ cell tumors that have evaluated ${ }^{18} \mathrm{~F}-\mathrm{FLT}$ and ${ }^{18} \mathrm{~F}-\mathrm{FDG}$ to assess lesions for residual disease have shown limited benefits (60), probably more because of the lower uptake and sensitivity of ${ }^{18} \mathrm{~F}-\mathrm{FLT}$ in detecting tumors due to lower proliferation (61). Clinical studies are needed to assess ${ }^{18}$ F-FLT PET applications in testicular cancers.

\section{HEAD AND NECK CANCERS}

Head and neck cancers are a diverse group of neoplastic diseases. Like other areas of the body, ${ }^{18} \mathrm{~F}$-FLT uptake has frequently been reported to be lower than ${ }^{18} \mathrm{~F}-\mathrm{FDG}$ uptake in these tumors. On the other hand, because of a variety of inflammatory processes that can involve the lymph nodes in the head and neck, discrimination between inflammatory and neoplastic involvement in lymph nodes is not easy (62). In 23 patients examined with ${ }^{18} \mathrm{~F}$-FLT PET and ${ }^{18} \mathrm{~F}-$ FDG PET, the ${ }^{18}$ F-FLT SUV in metastatic lymph nodes was $4.8 \pm 2.9$, compared with $6.9 \pm 4.9$ for ${ }^{18} \mathrm{~F}-\mathrm{FDG}$ SUV $(P<0.001)$. The false-positive and false-negative rates by ${ }^{18} \mathrm{~F}$-FLT and ${ }^{18} \mathrm{~F}$-FDG PET were $4 \%(1 / 23)$ and $17 \%$ (4/23), respectively (63). All metastatic lymph nodes larger than $9 \mathrm{~mm}$ were detectable by ${ }^{18} \mathrm{~F}$-FLT PET. ${ }^{18} \mathrm{~F}$-FLT uptake was compared with iododeoxyuridine immunohistochemistry staining (to measure proliferation) and TK1 staining in 17 patients with squamous cell carcinoma of the oral cavity (64). There was a weak correlation between ${ }^{18} \mathrm{~F}$-FLT uptake and iododeoxyuridine staining intensity, but it varied with the techniques used. TK1 staining did not correlate with either of the other markers, but immunohistochemistry may not indicate enzymatic activity. In a series of 19 untreated patients, both ${ }^{18}$ F-FLT and ${ }^{18} \mathrm{~F}-\mathrm{FDG}$ uptake provided prognostic and survival information in primary head and neck cancers, with an ${ }^{18} \mathrm{~F}-\mathrm{FLT}$ mean SUVmax of $5.81 \pm 2.28$, compared with an ${ }^{18} \mathrm{~F}$-FDG mean SUVmax of $8.91 \pm 3.58(65)$. No correlation was found between the number of Ki-67-positive cells and ${ }^{18}$ F-FLT. Further studies may reveal the reason for the mismatch between proliferation and ${ }^{18} \mathrm{~F}$-FLT uptake in head and neck cancers. In patients undergoing radiation treatment, ${ }^{18} \mathrm{~F}-$ FLT uptake decreased rapidly after the start of therapy and before CT volumetric changes (64). In this study of 10 patients with oropharyngeal tumors, SUVmax and SUVmean decreased significantly as early as $1 \mathrm{wk}$ after therapy initiation and even further before the fourth week of treatment. Despite individual variations, the SUVmax of the second ${ }^{18}$ F-FLT PET scan was significantly lower than that of the first scan and decreased even more in the third scan 
(7.6 $\pm 2.6,3.1 \pm 1.7$, and $1.7 \pm 0.4$, respectively). Longterm (3-y) follow-up of patients undergoing chemoradiation showed the usefulness of ${ }^{18} \mathrm{~F}$-FLT uptake in predicting the long-term effect of the treatment (Fig. 5) (66). In this study of 28 patients with head and neck squamous cell carcinomas, the patients were imaged before therapy, 4 wk after the start of therapy, and then $5 \mathrm{wk}$ after completing radiation therapy. ${ }^{18} \mathrm{~F}-\mathrm{FLT}$ accumulations disappeared in 34 of 54 lesions (63\%), and negative predictive value was $97 \%$. In comparison, ${ }^{18} \mathrm{~F}-\mathrm{FDG}$ PET during radiation treatment also had a high negative predictive value (100\%), but only 9 lesions (16\%) showed complete absence of accumulation. Significant differences were observed in 3-y local control between the accumulation and no-accumulation groups on posttreatment ${ }^{18} \mathrm{~F}$-FLT PET $(P<0.0001)$, and it was

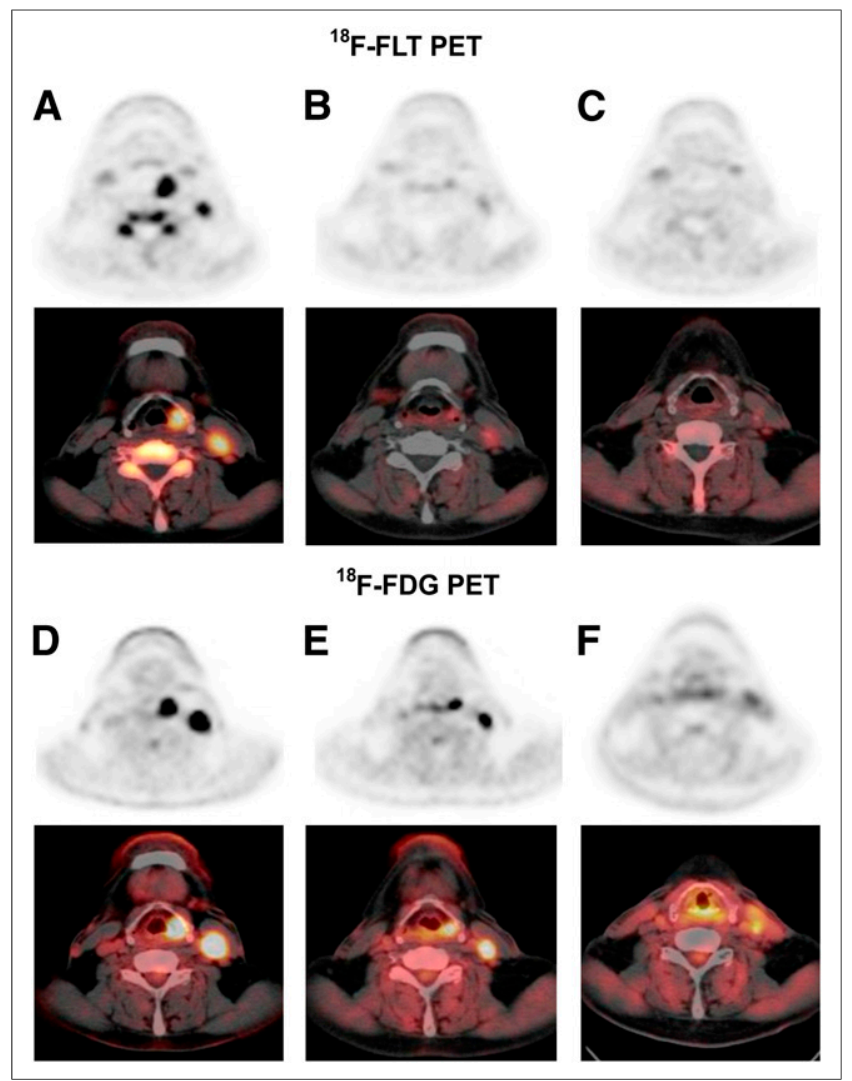

FIGURE 5. PET images of patient with hypopharyngeal cancer (patient 14) before radiation therapy (A and D), 3 wk after initiation of radiation therapy ( $\mathrm{B}$ and $\mathrm{E}$ ), and $4 \mathrm{wk}$ after end of radiation therapy (C and F). Pretreatment ${ }^{18} \mathrm{~F}-\mathrm{FLT}$ and ${ }^{18} \mathrm{~F}-\mathrm{FDG}$ axial PET images showed increased metabolism in primary tumor and metastatic lymph node $\left({ }^{18} \mathrm{~F}-\mathrm{FLT}\right.$ SUVs, 9.16 and 6.06 , respectively; ${ }^{18} \mathrm{~F}-\mathrm{FDG}$ SUVs, 21.81 and 13.37, respectively). ${ }^{18} \mathrm{~F}-\mathrm{FLT}$ and ${ }^{18} \mathrm{~F}-\mathrm{FDG}$ SUVs decreased after 30 Gy of irradiation ( ${ }^{18} \mathrm{~F}-\mathrm{FLT}$ SUVs, 2.86 and 2.14, respectively; ${ }^{18} \mathrm{~F}-\mathrm{FDG}$ SUVs, 11.44 and 6.39 , respectively). ${ }^{18} \mathrm{~F}-\mathrm{FLT}$ uptake in primary site and lymph nodes was same as in surrounding muscle (SUVs of $0.93,0.9$, and 0.9, respectively) at 4 wk after completion of treatment, whereas increased uptake of ${ }^{18} \mathrm{~F}-\mathrm{FDG}$ persisted (SUV of 4.66 in primary lesion and 3.75 in lymph node). Patient was alive and without evidence of recurrent disease 19 mo after therapy. (Reprinted from (66).) concluded that ${ }^{18}$ F-FLT PET during radiation treatment and early follow-up may help with prediction of outcome.

\section{LUNG CANCER}

Lung cancer has been the most studied malignancy using ${ }^{18} \mathrm{~F}$-FLT PET. In a cohort of 25 suspected lung cancer patients, ${ }^{18}$ F-FLT PET images were performed before surgical resection and compared with expression of Ki-67 and TK1 determined by immunohistochemical staining (67). TK1 enzymatic activity was also determined in extracts from flashfrozen samples of the tumors. Static ${ }^{18} \mathrm{~F}$-FLT SUVmax uptake from 60 to $90 \mathrm{~min}$ correlated with the overall $(\rho=0.57, P=$ $0.006)$ and maximal $(\rho=0.69, P<0.001)$ immunohistochemical expressions of Ki-67 and TK1 but not with TK1 enzymatic activity $(\rho=0.34, P=0.146)$. Correlation between TK1 activity and TK1 protein expression was limited to immunohistochemistry scoring for maximal expression. Other studies, as described below, have also demonstrated reasonable correlations between ${ }^{18} \mathrm{~F}$-FLT uptake and Ki-67.

In another study, 18 patients with newly diagnosed nonsmall cell lung cancer were imaged with both ${ }^{18} \mathrm{~F}-\mathrm{FLT}$ PET and ${ }^{18}$ F-FDG PET at 60 min after injection with sensitivities of $72 \%$ and $89 \%$, respectively (68). Four of the 5 falsenegative ${ }^{18}$ F-FLT PET findings occurred in bronchoalveolar carcinoma, as may be attributed to slower growth and differences in the kinetics and dynamics of ${ }^{18} \mathrm{~F}$-FLT in these tumors. Similar results in another study on 68 patients with non-small cell lung cancer showed SUVmax to be significantly correlated with the Ki-67 $(r=0.550$ and $0.633, P=$ 0.000 and 0.000 , respectively) (69). There was also some correlation with CD31-MVD and CD34-MVD (angiogenesis markers) ( $r=0.228$ and $0.235, P=0.062$ and 0.054 , respectively). These data suggest that ${ }^{18} \mathrm{~F}$-FLT uptake is influenced by a host of other factors including angiogenesis.

Like other cancers, uptake of ${ }^{18} \mathrm{~F}$-FLT in lung cancers is significantly lower than that of ${ }^{18} \mathrm{~F}-\mathrm{FDG}$, with lower sensitivity, higher specificity, and higher positive predictive value $(68,70-72)$. However, the correlation with proliferation is partially shown in response to treatment. The association with progression-free survival and ${ }^{18} \mathrm{~F}-\mathrm{FLT}$ uptake was shown in patients treated with erlotinib (73). In 30 patients with stage IV non-small cell lung cancer imaged before, $1 \mathrm{wk}$, and $6 \mathrm{wk}$ after the start of erlotinib treatment, ${ }^{18} \mathrm{~F}-\mathrm{FLT}$ and ${ }^{18} \mathrm{~F}-\mathrm{FDG}$ PET imaging was done. A cutoff value of a $20 \%$ or $30 \%$ decrease in ${ }^{18} \mathrm{~F}$-FLT uptake was used to define metabolic response. Patients with lower early and late residual tumor glycolysis ( ${ }^{18} \mathrm{~F}-\mathrm{FDG}$ uptake) and proliferation $\left({ }^{18} \mathrm{~F}-\mathrm{FLT}\right.$ uptake) had a significantly prolonged progression-free survival. In another study of 34 patients, the changes in ${ }^{18} \mathrm{~F}-\mathrm{FDG}$ and ${ }^{18} \mathrm{~F}$-FLT uptake after 1 and $6 \mathrm{wk}$ of erlotinib treatment were compared with nonprogression measured by CT after $6 \mathrm{wk}$ of treatment (74). Early ${ }^{18} \mathrm{~F}$-FLT response predicted longer progression-free survival (hazard ratio, $0.31 ; 95 \%$ confidence interval, $0.10-0.95 ; \mathrm{P}=0.04$ ) but not overall survival and could not predict nonprogression after 6 wk of therapy. Decreased ${ }^{18}$ F-FLT uptake was 
observed in tumors sensitive to erlotinib combined with Bcl-x inhibitor in preclinical studies (75). Changes in ${ }^{18} \mathrm{~F}$-FLT retention have been seen in lung cancer soon after the start of chemotherapy and radiation therapy (76) and have led to testing pharmacokinetic parameters in lung tumors. A compartmental model analysis performed on 18 tumors in 17 patients found overall flux constants $\mathrm{K}\left({ }^{18} \mathrm{~F}-\mathrm{FLT}\right)$ highly correlated with Ki-67 $(\rho=0.92, P<0.001)$ (77). This study concluded that the 4-parameter model is better than the 3parameter model, thus allowing for dephosphorylation. However, this model requires at least 90 min of imaging. In an early study by Buck et al., 26 patients with lung cancer were imaged with ${ }^{18} \mathrm{~F}$-FDG and ${ }^{18} \mathrm{~F}$-FLT. SUV was compared with proliferation measured by Ki-67. Uptake of ${ }^{18}$ F-FLT was noticeably lower than that of ${ }^{18} \mathrm{~F}-\mathrm{FDG}$ (mean, 1.8 vs. 4.1 , respectively). However, ${ }^{18} \mathrm{~F}$-FLT correlated better with proliferation index than ${ }^{18} \mathrm{~F}-\mathrm{FDG}(P<0.001 ; r=0.92$, vs. $P<$ $0.001 ; r=0.59$, respectively). This study demonstrated that ${ }^{18} \mathrm{~F}-\mathrm{FLT}$ uptake correlated better with proliferation in lung tumors as measured by Ki-67 (Fig. 6) (78).

\section{SKIN CANCERS}

Among skin cancers, melanoma is the most prevalent aggressive type, and most clinical studies are limited to staging and treatment evaluation of this type of cancer. A study of 10 patients with stage III melanoma based on physical examination demonstrated that all locoregional metastases were correctly visualized by ${ }^{18}$ F-FLT PET. The detection limit for lymph node metastases was $6 \mathrm{~mm}$ or a mitotic rate of 9 mitoses per $2 \mathrm{~mm}^{2}$ (79). Adding ${ }^{18} \mathrm{~F}$-FLT PET to CT has added to the sensitivity but has decreased the specificity because of false-positive results. Interestingly,

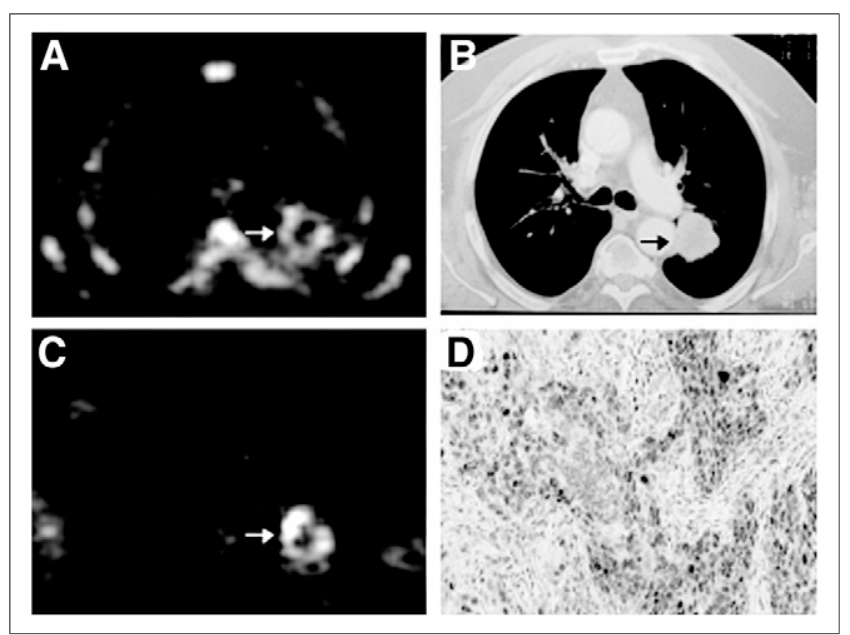

FIGURE 6. Patient 5, with non-small cell lung cancer in left upper lobe. (A) Transaxial ${ }^{18} \mathrm{~F}-\mathrm{FLT}$ PET scan demonstrates high ${ }^{18} \mathrm{~F}-\mathrm{FLT}$ uptake (arrow) in tumor margin. ${ }^{18} \mathrm{~F}-\mathrm{FLT}$ uptake in vertebral column, scapula, and ribs represents proliferating bone marrow. ( $B$ and $C$ ) Corresponding CT and ${ }^{18} \mathrm{~F}-\mathrm{FDG}$ PET scans show high ${ }^{18} \mathrm{~F}-\mathrm{FDG}$ uptake in tumor margin and primary lung tumor. (D) On Ki-67 immunohistochemistry, Ki-67-positive nuclei (brown) demonstrate high proliferation rate of $54 \%$, and hematoxylin background staining reveals Ki-67-negative nuclei (blue). (Reprinted from (78).) in an attempt to develop a method for the direct assessment of immune responses, patients were imaged with ${ }^{18}$ F-FLT PET before and after they received dendritic cell vaccine therapy (80). The level of tracer uptake in nearby nodes correlated to the level of circulating antigen-specific IgG antibodies and antigen-specific proliferation of $\mathrm{T}$ cells in peripheral blood. The authors concluded that ${ }^{18}$ F-FLT PET has been able to detect immune system activation after melanoma vaccination. The use of ${ }^{18} \mathrm{~F}$-FLT PET to detect activation was also demonstrated in a study of CTLA4 inhibition (81). Significant increases in the uptake of ${ }^{18} \mathrm{~F}$-FLT was seen in tumor-free spleen after treatment with tremelimumab in 12 patients with advanced melanoma, suggesting activation of immune response in the healthy tissue.

\section{DISCUSSION}

We are in an era of targeted therapy and molecular imaging. Using proliferation-specific tracers may help better identify an unknown lesion and help us predict response to the treatment. As ${ }^{18} \mathrm{~F}-\mathrm{FLT}$ finds more applications in proliferation imaging, its benefits and limitations will be better known. Currently available data have shown application of this agent in solid tumors and bone marrow activity. Major limitations have been in areas with high uptake in the normal background, such as in the genitourinary and hepatobiliary systems. Because of the generally lower uptake of ${ }^{18} \mathrm{~F}$-FLT than of ${ }^{18} \mathrm{~F}-\mathrm{FDG}$ in most solid tumors, ${ }^{18} \mathrm{~F}-\mathrm{FLT}$ is not expected to replace ${ }^{18} \mathrm{~F}-\mathrm{FDG}$ for detection and staging purposes, except for certain lesions. Studies performed with ${ }^{18}$ F-FLT suggest that part of the varying results among studies can be due to different imaging techniques and to a lack of standardized methods.

It is noticeable that not all tumors with high proliferation have high uptake of ${ }^{18} \mathrm{~F}-\mathrm{FLT}$. Although different tissue-processing methods used for comparison might play a role, probably there are some biologic aspects of this phenomenon. Although tumor imaging using ${ }^{18} \mathrm{~F}$-FLT has been done with the intention of evaluating proliferation, the exact mechanism of tumor uptake depends on multiple factors just as it does for ${ }^{18} \mathrm{~F}-\mathrm{FDG}$. The type of cancer, time of imaging, and type of treatment all may affect ${ }^{18} \mathrm{~F}-\mathrm{FLT}$ uptake in different ways. As an example, the effect of a microtubule stabilizer on ${ }^{18} \mathrm{~F}$-FLT uptake in a murine model of fibrosarcoma showed excellent results (82); another study concluded that p53 null cancers might behave differently (83).

These different mechanisms are especially important in the era of new targeted therapies, where a specific pathway is targeted to control certain mechanisms. Studies have already compared ${ }^{18} \mathrm{~F}$-FLT with other modalities. In these cases, close attention should be paid to whether the pathway affects nucleoside transport or metabolism. These may directly affect ${ }^{18} \mathrm{~F}-\mathrm{FLT}$ uptake regardless of the proliferation.

The evaluation of residual disease is also important as treatment becomes more successful. Although ${ }^{18} \mathrm{~F}-\mathrm{FDG}$ was found to be more sensitive than ${ }^{18} \mathrm{~F}$-FLT PET in finding residual disease in lymphoma patients, both tracers were 
able to discriminate patients with different survivals. Nevertheless, the uptake will rely on the interpersonal difference in kinetics and dynamics of ${ }^{18} \mathrm{~F}-\mathrm{FLT}$ in tumor cells and the effect of medications on both. Single uptake measurements versus uptake before and after treatment, and single-parameter versus combined-kinetic-parameter measurements, can be used to determine tumor viability and proliferation $(37,82)$.

Another main player is the difference in the nature of the tissues; there are natural barriers and different transporters in neoplasms. Some tumors have high rates of proliferation, and others appear to be driven by decreased apoptosis. Even cells of the same tumors are heterogeneous, making generalized statements less accurate. Standardized methods of imaging will help overcome some of the technical problems in comparing different studies, but other aspects of pharmacokinetics and dynamics should always be considered in the final evaluations.

\section{CONCLUSION}

Imaging tumor proliferation with labeled pyrimidine analogs, such as ${ }^{18}$ F-FLT PET, offers a new approach to assessing tumor growth kinetics. Several studies have demonstrated that ${ }^{18} \mathrm{~F}$-FLT can detect cancers, but so far it does not appear likely to replace ${ }^{18} \mathrm{~F}-\mathrm{FDG}$ for this use with most tumor types. The ability of ${ }^{18}$ F-FLT imaging to provide an early measure of treatment response has been demonstrated in several preclinical and clinical studies with a variety of tumor types. This approach requires further validation to find routine clinical use.

\section{REFERENCES}

1. Pitter KL, Galban CJ, Galban S, et al. Perifosine and CCI 779 co-operate to induce cell death and decrease proliferation in PTEN-intact and PTEN-deficient PDGF-driven murine glioblastoma. PLOS ONE. 2011;6:e14545.

2. Ross BD, Zhao YJ, Neal ER, et al. Contributions of cell kill and posttreatment tumor growth rates to the repopulation of intracerebral 9L tumors after chemotherapy: an MR imaging study. Proc Natl Acad Sci USA. 1998;95:7012-7017.

3. Perumal M, Pillai RG, Barthel H, et al. Redistribution of nucleoside transporters to the cell membrane provides a novel approach for imaging thymidylate synthase inhibition by positron emission tomography. Cancer Res. 2006;66:8558-8564.

4. Plotnik DA, Emerick LE, Krohn KA, Unadkat JD, Schwartz JL. Different modes of transport for ${ }^{3} \mathrm{H}$-thymidine, ${ }^{3} \mathrm{H}$-FLT, and ${ }^{3} \mathrm{H}$-FMAU in proliferating and nonproliferating human tumor cells. J Nucl Med. 2010;51:1464-1471.

5. Mankoff DA, Shields AF, Lee TT, Graham MM. Tracer kinetic model for quantitative imaging of thymidine utilization using [C-11]thymidine and PET [abstract]. J Nucl Med. 1994;35(suppl):138P.

6. Toyohara J, Waki A, Takamatsu S, Yonekura Y, Magata Y, Fujibayashi Y. Basis of FLT as a cell proliferation marker: comparative uptake studies with $\left[{ }^{3} \mathrm{H}\right]$ thymidine and $\left[{ }^{3} \mathrm{H}\right]$ arabinothymidine, and cell-analysis in 22 asynchronously growing tumor cell lines. Nucl Med Biol. 2002;29:281-287.

7. Chalkidou A, Landau DB, Odell EW, Cornelius VR, O'Doherty MJ, Marsden PK. Correlation between Ki-67 immunohistochemistry and ${ }^{18}$ F-fluorothymidine uptake in patients with cancer: a systematic review and meta-analysis. Eur J Cancer. 2012;48:3499-3513.

8. Tehrani OS, Douglas KA, Lawhorn-Crews JM, Shields AF. Tracking cellular stress with labeled FMAU reflects changes in mitochondrial TK2. Eur J Nucl Med Mol Imaging. 2008;35:1480-1488.

9. Shields AF. PET imaging of tumor growth: not as easy as it looks. Clin Cancer Res. 2012;18:1189-1191.

10. Zhang CC, Yan Z, Li W, et al. $\left[{ }^{18}\right.$ F]FLT-PET imaging does not always "light up" proliferating tumor cells. Clin Cancer Res. 2012;18:1303-1312.

11. Shields AF, Grierson J, Dohmen B, et al. Imaging proliferation in vivo with [F18]FLT and positron emission tomography. Nat Med. 1998;4:1334-1336.

12. Woolthuis C, Agool A, Olthof S, et al. Auto-SCT induces a phenotypic shift from CMP to GMP progenitors, reduces clonogenic potential and enhances in vitro and in vivo cycling activity defined by ${ }^{18}$ F-FLT PET scanning. Bone Marrow Transplant. 2011;46:110-115.

13. Agool A, Slart RH, Kluin PM, de Wolf JT, Dierckx RA, Vellenga E. F-18 FLT PET: a noninvasive diagnostic tool for visualization of the bone marrow compartment in patients with aplastic anemia: a pilot study. Clin Nucl Med. 2011;36:286-289.

14. Agool A, Schot BW, Jager PL, Vellenga E. ${ }^{18}$ F-FLT PET in hematologic disorders: a novel technique to analyze the bone marrow compartment. J Nucl Med. 2006;47:1592-1598.

15. McGuire SM, Menda Y, Boles Ponto LL, Gross B, Buatti J, Bayouth JE. 3'-deoxy$3^{\prime}-\left[{ }^{18} \mathrm{~F}\right]$ fluorothymidine PET quantification of bone marrow response to radiation dose. Int J Radiat Oncol Biol Phys. 2011;81:888-893.

16. McGuire SM, Menda Y, Ponto LL, Gross B, Juweid M, Bayouth JE. A methodology for incorporating functional bone marrow sparing in IMRT planning for pelvic radiation therapy. Radiother Oncol. 2011;99:49-54.

17. Menda Y, Ponto LL, Dornfeld KJ, et al. Investigation of the pharmacokinetics of $3^{\prime}$-deoxy-3'- $\left[{ }^{18} \mathrm{~F}\right]$ fluorothymidine uptake in the bone marrow before and early after initiation of chemoradiation therapy in head and neck cancer. Nucl Med Biol. 2010;37:433-438.

18. Buck AK, Bommer M, Juweid ME, et al. First demonstration of leukemia imaging with the proliferation marker ${ }^{18} \mathrm{~F}$-fluorodeoxythymidine. J Nucl Med. 2008;49:1756-1762.

19. Holter JL, Thorp K, Smith ML, et al. $\left[{ }^{18} \mathrm{~F}\right]$ fluorothymidine PET imaging in the diagnosis of leptomeningeal involvement with diffuse large B-cell lymphoma. Cancer Imaging. 2011;11:140-143.

20. Vanderhoek M, Juckett MB, Perlman SB, Nickles RJ, Jeraj R. Early assessment of treatment response in patients with AML using $\left[{ }^{18}\right.$ F]FLT PET imaging. Leuk Res. 2011;35:310-316.

21. Hussein K, Jahagirdar B, Gupta P, Burns L, Larsen K, Weisdorf D. Day 14 bone marrow biopsy in predicting complete remission and survival in acute myeloid leukemia. Am J Hematol. 2008;83:446-450.

22. Herrmann K, Buck AK, Schuster T, et al. A pilot study to evaluate 3 '-deoxy$3^{\prime}-{ }^{18}$ F-fluorothymidine PET for initial and early response imaging in mantle cell lymphoma. J Nucl Med. 2011;52:1898-1902.

23. Wang RM, Zhu HY, Li F, Liu CB, Guan ZW, Yao SL. Value of ${ }^{18}$ F-FLT positron emission tomography/computed tomography in diagnosis and staging of diffuse large B-cell lymphoma. J Exp Hematol. 2012;20:603-607.

24. Herrmann K, Wieder HA, Buck AK, et al. Early response assessment using $3^{\prime}$-deoxy-3'-[ $\left.{ }^{18} \mathrm{~F}\right]$ fluorothymidine-positron emission tomography in high-grade non-Hodgkin's lymphoma. Clin Cancer Res. 2007;13:3552-3558.

25. Buck AK, Herrmann $\mathrm{K}$, Buschenfelde CM, et al. Imaging bone and soft tissue tumors with the proliferation marker $\left[{ }^{18} \mathrm{~F}\right]$ fluorodeoxythymidine. Clin Cancer Res. 2008;14:2970-2977.

26. Cobben DC, Elsinga PH, Suurmeijer AJ, et al. Detection and grading of soft tissue sarcomas of the extremities with ${ }^{18} \mathrm{~F}-3^{\prime}$-fluoro-3'-deoxy-L-thymidine. Clin Cancer Res. 2004;10:1685-1690.

27. Been LB, Suurmeijer AJ, Elsinga PH, Jager PL, van Ginkel RJ, Hoekstra HJ. ${ }^{18} \mathrm{~F}$-fluorodeoxythymidine PET for evaluating the response to hyperthermic isolated limb perfusion for locally advanced soft-tissue sarcomas. J Nucl Med. 2007;48:367-372.

28. Benz MR, Czernin J, Allen-Auerbach MS, et al. $3^{\prime}$-deoxy- $3^{\prime}-\left[{ }^{18} \mathrm{~F}\right]$ fluorothymidine positron emission tomography for response assessment in soft tissue sarcoma: a pilot study to correlate imaging findings with tissue thymidine kinase 1 and Ki-67 activity and histopathologic response. Cancer. 2012;118:3135-3144.

29. Smyczek-Gargya B, Fersis N, Dittmann H, et al. PET with $\left[{ }^{18} \mathrm{~F}\right]$ fluorothymidine for imaging of primary breast cancer: a pilot study. Eur J Nucl Med Mol Imaging. 2004;31:720-724.

30. Kenny L, Coombes RC, Vigushin DM, Al-Nahhas A, Shousha S, Aboagye EO. Imaging early changes in proliferation at 1 week post chemotherapy: a pilot study in breast cancer patients with $3^{\prime}$-deoxy- $3^{\prime}-\left[{ }^{18} \mathrm{~F}\right]$ fluorothymidine positron emission tomography. Eur J Nucl Med Mol Imaging. 2007;34:1339-1347.

31. Lubberink M, Direcks W, Emmering J, et al. Validity of simplified $3^{\prime}$-deoxy-3' $\left[{ }^{18} \mathrm{~F}\right]$ fluorothymidine uptake measures for monitoring response to chemotherapy in locally advanced breast cancer. Mol Imaging Biol. 2012;14:777-782.

32. Miyake K, Shinomiya A, Okada M, Hatakeyama T, Kawai N, Tamiya T. Usefulness of FDG, MET and FLT-PET studies for the management of human gliomas. J Biomed Biotechnol. 2012;2012:205818.

33. Enslow MS, Zollinger LV, Morton KA, et al. Comparison of ${ }^{18} \mathrm{~F}$-fluorodeoxyglucose and ${ }^{18} \mathrm{~F}$-fluorothymidine PET in differentiating radiation necrosis from recurrent glioma. Clin Nucl Med. 2012;37:854-861.

34. Schwarzenberg J, Czernin J, Cloughesy TF, et al. $3^{\prime}$-deoxy- $3^{\prime}-{ }^{18}$ F-fluorothymidine PET and MR imaging for early survival predictions in patients with recurrent malignant glioma treated with bevacizumab. J Nucl Med. 2012;53:29-36.

35. Harris RJ, Cloughesy TF, Pope WB, et al. ${ }^{18} \mathrm{~F}$-FDOPA and ${ }^{18} \mathrm{~F}$-FLT positron emission tomography parametric response maps predict response in recurrent malignant gliomas treated with bevacizumab. Neuro-Oncol. 2012;14:1079-1089. 
36. Saga T, Kawashima H, Araki N, et al. Evaluation of primary brain tumors with FLT-PET: usefulness and limitations. Clin Nucl Med. 2006;31:774-780.

37. Spence AM, Muzi M, Link JM, et al. NCI-sponsored trial for the evaluation of safety and preliminary efficacy of $3^{\prime}$-deoxy- $3^{\prime}-\left[{ }^{18} \mathrm{~F}\right]$ fluorothymidine (FLT) as a marker of proliferation in patients with recurrent gliomas: preliminary efficacy studies. Mol Imaging Biol. 2009;11:343-355.

38. Wardak M, Schiepers C, Dahlbom M, et al. Discriminant analysis of ${ }^{18} \mathrm{~F}$-fluorothymidine kinetic parameters to predict survival in patients with recurrent high-grade glioma. Clin Cancer Res. 2011;17:6553-6562.

39. Hong IK, Kim JH, Ra YS, Kwon do H, Oh SJ, Kim JS. Diagnostic usefulness of $3^{\prime}$-deoxy-3'-[ $\left.{ }^{18} \mathrm{~F}\right]$ fluorothymidine positron emission tomography in recurrent brain tumor. J Comput Assist Tomogr. 2011;35:679-684.

40. Yamamoto Y, Kameyama R, Izuishi K, et al. Detection of colorectal cancer using ${ }^{18} \mathrm{~F}-$ FLT PET: comparison with ${ }^{18}$ F-FDG PET. Nucl Med Commun. 2009;30:841-845.

41. Francis DL, Freeman A, Visvikis D, et al. In vivo imaging of cellular proliferation in colorectal cancer using positron emission tomography. Gut. 2003;52:1602-1606.

42. Francis DL, Visvikis D, Costa DC, et al. Potential impact of $\left[{ }^{18} \mathrm{~F}\right] 3^{\prime}$-deoxy-3'fluorothymidine versus $\left[{ }^{18} \mathrm{~F}\right]$ fluoro-2-deoxy-D-glucose in positron emission tomography for colorectal cancer. Eur J Nucl Med Mol Imaging. 2003;30:988-994.

43. Dehdashti F, Grigsby PW, Myerson RJ, Nalbantoglu I, Ma C, Siegel BA. Positron emission tomography with $\left[{ }^{18} \mathrm{~F}\right]-3^{\prime}$-deoxy-3' fluorothymidine (FLT) as a predictor of outcome in patients with locally advanced resectable rectal cancer: a pilot study. Mol Imaging Biol. 2013;15:106-113.

44. Han D, Yu J, Zhong X, et al. Comparison of the diagnostic value of 3-deoxy-3- ${ }^{18} \mathrm{~F}-$ fluorothymidine and ${ }^{18} \mathrm{~F}$-fluorodeoxyglucose positron emission tomography/computed tomography in the assessment of regional lymph node in thoracic esophageal squamous cell carcinoma: a pilot study. Dis Esophagus. 2012;25:416-426.

45. Han D, Yu J, Yu Y, et al. Comparison of ${ }^{18} \mathrm{~F}$-fluorothymidine and ${ }^{18} \mathrm{~F}$-fluorodeoxyglucose PET/CT in delineating gross tumor volume by optimal threshold in patients with squamous cell carcinoma of thoracic esophagus. Int J Radiat Oncol Biol Phys. 2010;76:1235-1241.

46. van Westreenen HL, Westerterp M, Jager PL, et al. Synchronous primary neoplasms detected on ${ }^{18} \mathrm{~F}$-FDG PET in staging of patients with esophageal cancer. $J$ Nucl Med. 2005;46:1321-1325.

47. Yue J, Chen L, Cabrera AR, et al. Measuring tumor cell proliferation with ${ }^{18} \mathrm{~F}$ FLT PET during radiotherapy of esophageal squamous cell carcinoma: a pilot clinical study. J Nucl Med. 2010;51:528-534.

48. Herrmann K, Ott K, Buck AK, et al. Imaging gastric cancer with PET and the radiotracers ${ }^{18}$ F-FLT and ${ }^{18}$ F-FDG: a comparative analysis. J Nucl Med. 2007;48:1945-1950.

49. Kameyama R, Yamamoto Y, Izuishi K, et al. Detection of gastric cancer using ${ }^{18} \mathrm{~F}-\mathrm{FLT}$ PET: comparison with ${ }^{18}$ F-FDG PET. Eur J Nucl Med Mol Imaging. 2009;36:382-388.

50. Ott K, Herrmann K, Schuster T, et al. Molecular imaging of proliferation and glucose utilization: utility for monitoring response and prognosis after neoadjuvant therapy in locally advanced gastric cancer. Ann Surg Oncol. 2011;18:3316-3323.

51. Kameyama R, Yamamoto Y, Izuishi K, Sano T, Nishiyama Y. Correlation of ${ }^{18} \mathrm{~F}$ FLT uptake with equilibrative nucleoside transporter-1 and thymidine kinase-1 expressions in gastrointestinal cancer. Nucl Med Commun. 2011;32:460-465.

52. Giammarile F, Billotey C, Lombard-Bohas C, et al. ${ }^{18}$ F-FLT and ${ }^{18}$ F-FDG positron emission tomography for the imaging of advanced well-differentiated gastro-entero-pancreatic endocrine tumours. Nucl Med Commun. 2011;32:91-97.

53. Eckel F, Herrmann K, Schmidt S, et al. Imaging of proliferation in hepatocellular carcinoma with the in vivo marker ${ }^{18}$ F-fluorothymidine. J Nucl Med. 2009; 50:1441-1447.

54. Herrmann K, Erkan M, Dobritz M, et al. Comparison of $3^{\prime}$-deoxy-3'-[ ${ }^{18}$ F $]$ fluorothymidine positron emission tomography (FLT PET) and FDG PET/CT for the detection and characterization of pancreatic tumours. Eur J Nucl Med Mol Imaging. 2012;39:846-851.

55. Herrmann K, Eckel F, Schmidt S, et al. In vivo characterization of proliferation for discriminating cancer from pancreatic pseudotumors. J Nucl Med. 2008;49:1437-1444.

56. Quon A, Chang ST, Chin F, et al. Initial evaluation of ${ }^{18} \mathrm{~F}$-fluorothymidine (FLT) PET/CT scanning for primary pancreatic cancer. Eur J Nucl Med Mol Imaging. 2008;35:527-531.

57. Lawrentschuk N, Poon AM, Scott AM. Fluorine-18 fluorothymidine: a new positron emission radioisotope for renal tumors. Clin Nucl Med. 2006;31:788-789.

58. Liu G, Jeraj R, Vanderhoek M, et al. Pharmacodynamic study using FLT PET/CT in patients with renal cell cancer and other solid malignancies treated with sunitinib malate. Clin Cancer Res. 2011;17:7634-7644.

59. Richard SD, Bencherif B, Edwards RP, et al. Noninvasive assessment of cell proliferation in ovarian cancer using $\left[{ }^{18} \mathrm{~F}\right] 3^{\prime}$ deoxy-3-fluorothymidine positron emission tomography/computed tomography imaging. Nucl Med Biol. 2011;38:485-491.

60. Pfannenberg C, Aschoff P, Dittmann H, et al. PET/CT with ${ }^{18}$ F-FLT: does it improve the therapeutic management of metastatic germ cell tumors? $\mathrm{J} \mathrm{Nucl}$ Med. 2010;51:845-853.
61. Joly F, Paciencia M, Bor C, Aide N. Postchemotherapy residual masses in nonseminomatous germ cell tumor patients: ${ }^{18}$ F-FLT PET is unlikely to identify mature teratoma, but imaging of $\alpha_{\mathrm{v}} \beta_{3}$ integrin expression could [letter]. J Nucl Med. 2011;52:840.

62. Troost EG, Vogel WV, Merkx MA, et al. ${ }^{18}$ F-FLT PET does not discriminate between reactive and metastatic lymph nodes in primary head and neck cancer patients. J Nucl Med. 2007;48:726-735.

63. Hoshikawa H, Kishino T, Mori T, et al. Comparison of ${ }^{18} \mathrm{~F}$-FLT PET and ${ }^{18} \mathrm{~F}$ FDG PET for detection of cervical lymph node metastases in head and neck cancers. Acta Otolaryngol. 2012;132:1347-1354

64. Troost EG, Bussink J, Hoffmann AL, Boerman OC, Oyen WJ, Kaanders JH. ${ }^{18} \mathrm{~F}-$ FLT PET/CT for early response monitoring and dose escalation in oropharyngeal tumors. J Nucl Med. 2010;51:866-874.

65. Linecker A, Kermer C, Sulzbacher I, et al. Uptake of ${ }^{18}$ F-FLT and ${ }^{18}$ F-FDG in primary head and neck cancer correlates with survival. Nuklearmedizin. 2008;47:80-85.

66. Kishino T, Hoshikawa H, Nishiyama Y, Yamamoto Y, Mori N. Usefulness of 3'deoxy- $3^{\prime}-{ }^{18} \mathrm{~F}$-fluorothymidine PET for predicting early response to chemoradiotherapy in head and neck cancer. J Nucl Med. 2012;53:1521-1527.

67. Brockenbrough JS, Souquet T, Morihara JK, et al. Tumor $3^{\prime}$-deoxy- $3^{\prime}{ }^{18}$ F-fluorothymidine $\left({ }^{18} \mathrm{~F}-\mathrm{FLT}\right)$ uptake by PET correlates with thymidine kinase 1 expression: static and kinetic analysis of ${ }^{18}$ F-FLT PET studies in lung tumors. $J$ Nucl Med. 2011;52:1181-1188.

68. Yamamoto Y, Nishiyama Y, Ishikawa S, et al. Correlation of ${ }^{18} \mathrm{~F}-\mathrm{FLT}$ and ${ }^{18} \mathrm{~F}-$ FDG uptake on PET with Ki-67 immunohistochemistry in non-small cell lung cancer. Eur J Nucl Med Mol Imaging. 2007;34:1610-1616.

69. Yang W, Zhang Y, Fu Z, Sun X, Mu D, Yu J. Imaging proliferation of ${ }^{18}$ F-FLT $\mathrm{PET} / \mathrm{CT}$ correlated with the expression of microvessel density of tumour tissue in non-small-cell lung cancer. Eur J Nucl Med Mol Imaging. 2012;39:1289-1296.

70. Yamamoto Y, Nishiyama Y, Ishikawa S, et al. $3^{\prime}$-deoxy- $3^{\prime}-{ }^{18}$ F-fluorothymidine as a proliferation imaging tracer for diagnosis of lung tumors: comparison with 2-deoxy-2-18 f-fluoro-D-glucose. J Comput Assist Tomogr. 2008;32:432-437.

71. Yamamoto Y, Nishiyama Y, Kimura N, et al. Comparison of ${ }^{18}$ F-FLT PET and ${ }^{18} \mathrm{~F}-\mathrm{FDG}$ PET for preoperative staging in non-small cell lung cancer. Eur J Nucl Med Mol Imaging. 2008;35:236-245.

72. Yap CS, Czernin J, Fishbein MC, et al. Evaluation of thoracic tumors with ${ }^{18} \mathrm{~F}-$ fluorothymidine and ${ }^{18} \mathrm{~F}$-fluorodeoxyglucose-positron emission tomography. Chest. 2006;129:393-401.

73. Kahraman D, Holstein A, Scheffler M, et al. Tumor lesion glycolysis and tumor lesion proliferation for response prediction and prognostic differentiation in patients with advanced non-small cell lung cancer treated with erlotinib. Clin Nucl Med. 2012;37:1058-1064.

74. Zander T, Scheffler M, Nogova L, et al. Early prediction of nonprogression in advanced non-small-cell lung cancer treated with erlotinib by using $\left[{ }^{18} \mathrm{~F}\right]$ fluorodeoxyglucose and $\left[{ }^{18} \mathrm{~F}\right]$ fluorothymidine positron emission tomography. J Clin Oncol. 2011;29:1701-1708.

75. Zannetti A, Iommelli F, Speranza A, Salvatore M, Del Vecchio S. 3'-deoxy$3^{\prime}-{ }^{18} \mathrm{~F}$-fluorothymidine PET/CT to guide therapy with epidermal growth factor receptor antagonists and $\mathrm{Bcl}-\mathrm{xL}$ inhibitors in non-small cell lung cancer. $\mathrm{J} \mathrm{Nucl}$ Med. 2012;53:443-450.

76. Everitt S, Hicks RJ, Ball D, et al. Imaging cellular proliferation during chemoradiotherapy: a pilot study of serial ${ }^{18} \mathrm{~F}-\mathrm{FLT}$ positron emission tomography/computed tomography imaging for non-small-cell lung cancer. Int J Radiat Oncol Biol Phys. 2009;75:1098-1104.

77. Muzi M, Vesselle H, Grierson JR, et al. Kinetic analysis of $3^{\prime}$-deoxy-3'-fluorothymidine PET studies: validation studies in patients with lung cancer. $J$ Nucl Med. 2005;46:274-282.

78. Buck AK, Halter G, Schirrmeister $\mathrm{H}$, et al. Imaging proliferation in lung tumors with PET: ${ }^{18}$ F-FLT versus ${ }^{18}$ F-FDG. J Nucl Med. 2003;44:1426-1431.

79. Cobben DC, Jager PL, Elsinga PH, Maas B, Suurmeijer AJ, Hoekstra HJ. $3^{\prime}$ - $^{18} \mathrm{~F}-$ fluoro-3'-deoxy-L-thymidine: a new tracer for staging metastatic melanoma? J Nucl Med. 2003;44:1927-1932.

80. Aarntzen EH, Srinivas M, De Wilt JH, et al. Early identification of antigenspecific immune responses in vivo by $\left[{ }^{18} \mathrm{~F}\right]$-labeled $3^{\prime}$-fluoro- $3^{\prime}$-deoxy-thymidine ([ ${ }^{18}$ F]FLT) PET imaging. Proc Natl Acad Sci USA. 2011;108:18396-18399.

81. Ribas A, Benz MR, Allen-Auerbach MS, et al. Imaging of CTLA4 blockadeinduced cell replication with ${ }^{18} \mathrm{~F}$-FLT PET in patients with advanced melanoma treated with tremelimumab. $\mathrm{J} \mathrm{Nucl} \mathrm{Med.} \mathrm{2010;51:340-346.}$

82. Ebenhan T, Honer M, Ametamey SM, et al. Comparison of $\left[{ }^{18} \mathrm{~F}\right]$-tracers in various experimental tumor models by PET imaging and identification of an early response biomarker for the novel microtubule stabilizer patupilone. Mol Imaging Biol. 2009;11:308-321.

83. Katz SI, Zhou L, Ferrara TA, et al. FLT-PET may not be a reliable indicator of therapeutic response in p53-null malignancy. Int J Oncol. 2011;39:91-100. 